\title{
Predicting the effect of prandial stage and particle size on absorption of ODM-204.
}

\section{Ojala, Krista E M}

2020-11

Ojala , K E M , Schilderink , R, Nykänen , P , van Veen , B , Malmström , C , Juppo , A \& Korjamo , T 2020 , ' Predicting the effect of prandial stage and particle size on absorption of ODM-204. ' , European Journal of Pharmaceutics and Biopharmaceutics, vol. 156 , pp. 75-83 . https://doi.org/10.1016/j.ejpb.2020.08.011

http://hdl.handle.net/10138/339065

https://doi.org/10.1016/j.ejpb.2020.08.011

cc_by_nc_nd

acceptedVersion

Downloaded from Helda, University of Helsinki institutional repository.

This is an electronic reprint of the original article.

This reprint may differ from the original in pagination and typographic detail.

Please cite the original version. 


\section{Predicting the effect of prandial stage and particle size on}

\section{absorption of ODM-204}

Krista Ojala ${ }^{\mathrm{a}}$, Ronald Schilderink ${ }^{\mathrm{b}}$, Pirjo Nykänen ${ }^{\mathrm{a},}$ Bert van Veen ${ }^{\mathrm{a}}$, Chira Malmström ${ }^{\mathrm{a}}$, Anne Juppo $^{\mathrm{c}}$, Timo Korjamo ${ }^{\mathrm{a}}$

5 a) Orion Corporation, Orion Pharma, Finland

b) Triskelion B.V., The Netherlands

c) Division of Pharmaceutical Technology and Industrial Pharmacy, University of Helsinki,

Finland

Corresponding author:

10 Krista Ojala, Orion Pharma, P.O. Box 425, 20101 Turku, Finland

Tel. +358 10 4261, Mob. +358 509667743

krista.ojala@orionpharma.com

\section{Keywords}

15 Absorption, dissolution, PBPK modeling, prediction of fraction absorbed, transit intestinal model 


\section{Abstract}

The prediction of absorption properties plays a key role in formulation development when the compound under development shows poor solubility and its absorption is therefore presumed to be solubility limited. In our work, we combined and compared data obtained from in vitro dissolution tests, transit intestinal model studies (TIM-1) and physiologically based pharmacokinetic modelling. Our aim was to determine the ability of these methods to predict performance of poorly soluble lipophilic weak base in vivo. The validity of the predictive

25 methods was evaluated against the in vivo clinical pharmacokinetic (PK) data obtained after administration of the first test formulation, T1. The aim of our study was to utilize the models in evaluating absorption properties of the second test formulation, T2, which has not yet been clinically administered.

The compound in the studies was ODM-204, which is a novel, orally administered, investigational, nonsteroidal dual inhibitor of CYP17A1 and androgen receptor. Owing to its physicochemical properties ODM-204 is prone to low or variable bioavailability.

The models examined provided congruent data on dose dependent absorption, food effect at a dose of $200 \mathrm{mg}$ and on the effect of API (active pharmaceutical ingredient) particle size on absorption. Our study shows that the predictive tools of in vitro dissolution, TIM-1 system and

35 the PBPK (physiologically based pharmacokinetic modelling) simulation, showed predictive power of different mechanisms of bioavailability and together provided valuable information for decision making. 


\section{Abbreviations}

ACAT Advanced compartmental absorption transit

API Active pharmaceutical ingredient

AR Androgen receptor

CL Clearance

CRPC Castration-resistant prostate cancer

45 ECB European continental breakfast

FA\% Fraction absorbed in percentages

FaSSIF Fasted state simulated intestinal fluid

FeSSIF Fed state simulated intestinal fluid

Fup $\quad$ Fraction unbound in plasma

$50 \quad$ GI

Gastrointestinal

GFR Glomerular filtration rate

G+ GastroPlus software

HPLC High pressure chromatography

i.v. Intra venous

55 IVIVE In vitro in vivo extrapolation

Kp Partition coefficient

PBPK Physiologically based pharmacokinetic

PSD Particle size distribution

Peff Intestinal permeability

60 SGF Simulated gastric fluid

SIF Simulated intestinal fluid

TIM-1 Transit intestinal model 
UPLC Ultra pressure chromatography

Vss $\quad$ Volume of distribution

65 


\section{Introduction}

Methods to estimate oral bioavailability are of interest to the pharmaceutical industry as many new chemical entities are poorly water soluble leading to low oral bioavailability and variable absorption (Benet et al., 2006). Reliable prediction of absorption, bioavailability and ultimately exposure facilitates decision-making, aids in formulation work, and supports the appropriate design of clinical studies. The enhanced use of predictive tools is also motivated by the $3 \mathrm{R}$ initiative to reduce and refine of animal experimentation (http://www.efpia.eu/articles/animalwelfare-3rs-replace-refine-reduce) as outlined in recent studies by Matsumura et al. (2018).

Traditionally one-compartment in vitro dissolution methods have been used to characterize

75 pharmaceutical products intended for clinical use. Over the years, efforts have been made to develop in vivo relevant dissolution methods to support and enhance pharmaceutical development. Since the 1990s research has developed more advanced dissolution models including the use of biorelevant media (Dressman et al., 1998, Galia, et al., 1998). A thorough review by Kostewicz et al. (2014) showed that a wide range of applications has been established in dissolution testing. However, as the authors conclude, there are major issues limiting the predictive power of traditional tools. Factors such as simulation of dynamic changes in gastrointestinal conditions; adequate reproduction of gastrointestinal motility; simulation of supersaturation and precipitation; and the implementation of the solubility-permeability interplay are still required.

85 Advanced methods have been developed to overcome the limitations recognized in the compendial dissolution apparatuses. The aim of these methods is to mimic gastrointestinal motility or the transfer of the drug product in the gastrointestinal (GI) tract more realistically. The in vitro dynamic gastrointestinal model TIM-1 (Minekus et al., 1995) is one of the applications used to study the dissolution and bioaccessibility properties of drugs in a way that 
reflects the in vivo environment more closely. This system has been applied to pharmaceutical research and its quality to predict the release and bioaccessibility of drugs has been shown. Barker et al. (2014) concluded that TIM-1 shows potential as a risk assessment tool in product development and it may be used as a substitute for canine studies in assessing clinically relevant differences between formulations. More recently, tiny-TIM, a simplified version of TIM-1, has been developed to enhance practicability of the transit intestinal model. The performance of both transit intestinal systems in studying oral formulations has been described in a comparative study described by Verwei et al. (2016).

Advanced in vitro dissolution methods (Butler, et al., 2019) provide valuable background information for formulation scientists. However, these models are not capable of capturing the complex biological processes of the GI tract in vivo. Therefore, relying on a single method is not advisable. Instead, it is recommended that information gained from the in vitro release tests are incorporated into in silico tools to obtain a deeper understanding of the relative importance of the various factors affecting drug absorption in vivo (Andreas, et al., 2018).

Among in vitro data, pharmaceutical scientists have used simple mathematical equations to predict the maximum absorbable dose (MAD), for example (Oh et al., 1993; Curatolo, 1998). During recent years, significant efforts have been put into the development of more sophisticated and powerful in silico tools to evaluate the behaviour of a drug substance in vivo. Physiologically based pharmacokinetic (PBPK) models like GastroPlus ${ }^{\mathrm{TM}}$ (Simulations Plus Inc., Lancaster, CA, USA) and Simcyp ${ }^{\circledR}($ Certara, UK) are examples of the approaches used in the pharmaceutical industry. The advantages and limitations of these models have been actively discussed in the literature recently (Bueters et al. 2013; Kostewicz, et al., 2014; Kesisoglou et al. 2016; Darwich et al., 2017; Margolskee, et al.; 2017; and Miller et al., 2019). 
In our study, we applied single- and two-stage dissolution studies, TIM-1 system and PBPK modeling to predict dose linearity (50 - 500 mg) and food effect (at $200 \mathrm{mg}$ ) in humans and to 115 evaluate the effect of particle size on exposure. The outcome of the predictive methods was evaluated against the in vivo clinical pharmacokinetic (PK) data obtained after administration of immediate release (IR) test formulation T1. In summary, the aim of our study was to understand and predict the performance of the poorly lipid soluble weak base ODM-204 in patients by combining several alternative methodologies. Further, we studied whether 120 information could be utilized to predict the absorption behavior of test formulation T2 with reduced particle size of ODM-204. 


\section{Materials}

ODM-204 is an investigational, nonsteroidal dual inhibitor of CYP17A1 and the androgen receptor (AR), which has entered the Phase I dose escalation trails in men with castrationresistant prostate cancer (CRPC) (Peltola, et al., 2020). ODM-204 is a salt of a low water soluble weak base strongly showing $\mathrm{pH}$ dependent solubility (Table 1). The aqueous solubility values were measured as single determinations at room temperature $\left(25^{\circ} \mathrm{C}\right)$. The 3 hours shake-flask method was used, and the final $\mathrm{pH}$ values of the solutions were measured. The experimental LogD determination was done by a $\mathrm{pH}$-metric high $\log \mathrm{P}$ method and the $\mathrm{pKa}$ determination by use of the UV-metric method using Yasuda-Sverdlovsk extrapolation (Table 1).

To explore the intestinal solubility of the compound, solubility in the simulated intestinal media was measured at physiological temperature, $+37^{\circ} \mathrm{C}$ (Table 1). According to the biopharmaceutical classification system (BCS) criteria, ODM-204 is classified as a low water soluble compound. The dose number for ODM-204 calculated by the solubility in fasted state simulated intestinal fluid (FaSSIF) ranges from 10 to 100 . These numbers suggest solubility limited absorption for all doses administered.

In this study, two ODM-204 IR capsule test formulations, T1 and T2, differing in particle size were used (Table 2, Table 3). The manufacturing process is a dry direct blend process that consists of API milling, sieving of the excipients, blending steps and encapsulation. Both test formulations were capsulated in HPMC capsule size 0 shells (Capsugel VCaps, Capsugel, France). In the test formulation T1 (batch 151278460) unmilled ODM-204 (batch 1661532) was used. Milled API (batch 1665260) was used in the test formulation T2 (batch 1691237). The amount of API in the capsules was $100 \mathrm{mg}$ (calculated as free base of ODM-204). In test 145 formulations T1 and T2, the median particle size for the API batches were $258 \mu \mathrm{m}$ and $84 \mu \mathrm{m}$, respectively (Table 3$)$. 
Table $1 \quad$ Physicochemical properties of ODM-204.

$\mathrm{Rt}=$ room temperature. FaSSIF $=$ fasted state simulated fluid, FeSSIF $=$ fed state simulated fluid.

\begin{tabular}{|c|c|c|}
\hline Property & Experimental results & Method, $\mathrm{n}=1$ \\
\hline Solubility @ pH 2.4 (rt) & $7700 \mu \mathrm{g} / \mathrm{mL}$ & Shake flask \\
\hline Solubility@ pH 3.2 (rt) & $4130 \mu \mathrm{g} / \mathrm{mL}$ & Shake flask \\
\hline Solubility@ pH 3.8 (rt) & $1030 \mu \mathrm{g} / \mathrm{mL}$ & Shake flask \\
\hline Solubility@ pH 4.7 (rt) & $150 \mu \mathrm{g} / \mathrm{mL}$ & Shake flask \\
\hline Solubility@ pH 6.9 (rt) & $0.4 \mu \mathrm{g} / \mathrm{mL}$ & Shake flask \\
\hline Solubility @ pH $8.0(\mathrm{rt})$ & $0.7 \mu \mathrm{g} / \mathrm{mL}$ & Shake flask \\
\hline Solubility@ pH 9.2 (rt) & $1.0 \mu \mathrm{g} / \mathrm{mL}$ & Shake flask \\
\hline Solubility in FeSSIF pH $5.0\left(37^{\circ} \mathrm{C}\right)$ & $1580 \mu \mathrm{g} / \mathrm{mL}$ & Shake flask \\
\hline Solubility in FaSSIF pH $6.5\left(37^{\circ} \mathrm{C}\right)$ & $20 \mu \mathrm{g} / \mathrm{mL}$ & Shake flask \\
\hline \multirow[t]{2}{*}{$\mathrm{pKa}$} & pKa: 6.0 & UV-metric, \\
\hline & & Yasuda-Shedlovsky extrapolation \\
\hline $\operatorname{LogD}_{\mathrm{pH}} 2$ & 2,2 & pH-metric high $\log \mathrm{P}$ \\
\hline $\log D_{\mathrm{pH}} 5.5$ & 4,4 & pH-metric high $\log \mathrm{P}$ \\
\hline $\log D_{\mathrm{pH}} 7.4$ & 5,0 & pH-metric high $\log \mathrm{P}$ \\
\hline Molar mass (MW) & $490.48 \mathrm{~g} / \mathrm{mol}$ as fumarate salt & \\
\hline & $370.40 \mathrm{~g} / \mathrm{mol}$ as free base. & \\
\hline
\end{tabular}


Table 2 Components of the ODM-204 test formulations, T1 and T2.

\begin{tabular}{l}
\hline Component \\
\hline ODM 204 fumarate salt, active ingredient, Fermion Oyj
\end{tabular}

ODM 204 fumarate salt, active ingredient, Fermion Oyj

Microcrystalline Cellulose, Advice PH102, FMC Biopolymer

Dicalcium Phosphate, Anhydrous, A Tab, Innophos

Croscarmellose Sodium, Ac-Di-Sol, FMC Biopolymer

Glycerol Distearate, Precirol ATO5, Gattefosse

Size 0, HPMC white shell· VCaps, Gapsugel

160 Table 3 Particle size distribution of ODM-204 API batches used in test formulations, T1 and T2.

\begin{tabular}{|c|c|c|}
\hline Test formulation & $\mathrm{T} 1$ & $\mathrm{~T} 2$ \\
\hline \multirow[t]{2}{*}{ Batch } & 151278460 & 1691237 \\
\hline & (unmilled API) & (milled API) \\
\hline API batch & 1661532 & 1665260 \\
\hline \multicolumn{3}{|c|}{ Volume particle size distribution } \\
\hline - $\quad \mathrm{d} 10(\mu \mathrm{m})$ & 47 & 165 \\
\hline$-\quad \mathrm{d} 50(\mu \mathrm{m})$ & 274 & 84 \\
\hline - $\quad \mathrm{d} 90(\mu \mathrm{m})$ & 311 & 197 \\
\hline
\end{tabular}


Commercially available simulated gastric fluid (SGF) (FF Chemicals, Finland), phosphate 170 buffer solution pH 6.5 (FF Chemicals, Finland) and acetate buffer solution pH 5 (Reagena, Finland) were used in the dissolution studies at different $\mathrm{pH}$ values. Fasted and fed state simulated fluids, FaSSIF and FeSSIF (version 1) were prepared using the commercially available SIF ${ }^{\circledR}$ powder acquired from Biorelevant.com (Biorelevant.com Ltd, UK). In the twostage dissolution tests, double concentration media were prepared so that the final composition

175 of the media i.e. the second stage in the tests, corresponded to composition of FaSSIF or FeSSIF.

\section{Models and methods}

\subsection{Overview of models and methods}

180 Table 4 shows the overview of models and studies carried out in this work. Each study is described in more detail in the following subchapters. 
Table 4

Models and studies carried out in the work.

TIM-1 $=$ transit intestinal model, $\mathrm{MAD}=$ maximum absorbable dose.

\begin{tabular}{|c|c|c|}
\hline Study & Test formulation $\mathrm{T} 1$ & Test formulation $\mathrm{T} 2$ \\
\hline In vitro dissolution & $\begin{array}{l}100 \mathrm{mg} \text { capsule in } 900 \mathrm{~mL} \text { of } 0.01 \mathrm{M} \mathrm{HCl} \\
100 \mathrm{mg} \text { capsule in } 900 \mathrm{~mL} \text { of phosphate buffer } \mathrm{pH} 5 \\
100 \mathrm{mg} \text { capsule in } 500 \mathrm{~mL} \text { of FaSSIF }\end{array}$ & $100 \mathrm{mg}$ capsule in $500 \mathrm{~mL}$ of FaSSIF \\
\hline $\begin{array}{l}\text { In vitro dissolution, } \\
\text { two-stage }\end{array}$ & $\begin{array}{l}100 \mathrm{mg} \text { capsule in } 250 \mathrm{~mL} \text { of } \mathrm{SGF}(\mathrm{pH} 1.2)+250 \\
\mathrm{~mL} \text { of FaSSIF } \\
100 \mathrm{mg} \text { capsule in } 250 \mathrm{~mL} \text { of phosphate buffer } \mathrm{pH} 5 \\
+250 \mathrm{~mL} \text { of FeSSIF }\end{array}$ & $\begin{array}{l}2 \times 100 \mathrm{mg} \text { capsule in } 250 \mathrm{~mL} \text { of SGF }(\mathrm{pH} 1.2)+250 \mathrm{~mL} \\
\text { of FaSSIF } \\
2 \times 100 \text { capsule } \mathrm{mg} \text { in } 250 \mathrm{~mL} \text { of SGF }(\mathrm{pH} 3)+250 \mathrm{~mL} \\
\text { of FaSSIF }\end{array}$ \\
\hline TIM-1 study & $\begin{array}{l}2 \times 100 \mathrm{mg} \text { capsule in Fasted state } \\
2 \times 100 \mathrm{mg} \text { capsule in Fed state }\end{array}$ & $\begin{array}{l}2 \times 100 \mathrm{mg} \text { capsule in Fasted state } \\
2 \times 100 \mathrm{mg} \text { capsule in Fed state }\end{array}$ \\
\hline Dose number (calc.) $^{*}$ & $\begin{array}{l}\frac{50 \mathrm{mg}}{250 \mathrm{ml}} \\
0.02 \mathrm{mg} / \mathrm{ml}\end{array}=10$ & \\
\hline (MAD) (calc.) & $\begin{array}{l}\quad M A D=S * K_{a} * S I W V * S I T T \approx 23 \mathrm{mg} \\
\text { S=solubility in FaSSIF }(\mathrm{mg} / \mathrm{mL})=0.02 \\
\mathrm{~K}_{\mathrm{a}}=\text { absorption rate constant }\left(\mathrm{min}^{-1}\right)=0.0167 \\
\text { SIWV = small intestinal water volume }(\sim 250 \mathrm{~mL}) \\
\text { SITT = small intestinal transit time }(\sim 270 \mathrm{~min})\end{array}$ & \\
\hline PBPK in silico model & $\begin{array}{l}\text { Fasted state } 200 \mathrm{mg} \\
\text { Fed state } 50-500 \mathrm{mg}\end{array}$ & $\begin{array}{l}\text { Fasted state } 200 \mathrm{mg} \\
\text { Fed state } 50-500 \mathrm{mg}\end{array}$ \\
\hline
\end{tabular}




\begin{tabular}{|l|l|l|}
\hline Human PK & $\begin{array}{l}50^{\#}, 100,200,300 \text { and 500 mg in fed state } \\
\text { (non-standardized breakfast) } \\
200 \mathrm{mg} \text { in fasted state* }\end{array}$ & - \\
\hline
\end{tabular}

\#) $50 \mathrm{mg}$ dose was administered as $50 \mathrm{mg}$ capsule, the other doses as (multiple) $100 \mathrm{mg}$ capsules.

\subsection{Particle size determination}

The volume particle size distribution of ODM-204 was determined by Morphologi G3, an automated light microscope (Malvern Panalytical, UK). The sample size used was $3 \mathrm{~mm}^{3}$ and the pressure used in the dry dispersion system 5 bar. The sample was analyzed with a $10-\mathrm{x}$ objective. The d10, d50 and d90 fractiles of the volume distribution are reported in Table 3.

\subsection{In vitro dissolution tests}

195 Conventional USP II apparatus with a paddle speed of $50 \mathrm{rpm}$ was used in all tests (Distek Inc., NJ, USA). Sinkers (QLA spiral sinker, 8.5 coils) were used to prevent floating of the capsules. To study the release properties of ODM-204 $100 \mathrm{mg}$ capsules in aqueous solutions and to mimic approximately the shift in in vivo conditions, both single- and two-stage tests were conducted (Table 4). In the two-stage tests, dissolution was run for 30 minutes in $250 \mathrm{~mL}$ of the initial medium and after that $250 \mathrm{~mL}$ of concentrated FaSSIF or FeSSIF was gently added into the dissolution vessels (Table 4). Sink conditions were achieved in tests at $\mathrm{pH} 1.2, \mathrm{pH} 3$ and in FeSSIF while the test conditions at pH 5 and in FaSSIF were non-sink. All tests were performed at a temperature of $37^{\circ} \mathrm{C}$.

Quantification of the dissolved amount of the drug substance was performed against a calibration curve and the concentration measurement was performed either by high pressure liquid chromatograph (HPLC) (Agilent 1100, Agilent Technologies Inc., CA, USA) or by using 
an in situ fiber optic ultraviolet (UV) detection technique (Opt-diss UV spectrophotometer, Distek Inc. NJ, USA). An ACE Excel C18 column was used in the isocratic chromatographic system at $40^{\circ} \mathrm{C}$. The flow rate of the mobile phase, $10 \mathrm{mM}$ sodium acetate buffer: acetonitrile 210 (30:70), was $1 \mathrm{~mL} / \mathrm{min}$ and detection of ODM-204 was done at $310 \mathrm{~nm}$. In the in situ fiber optic system detection was done at $300 \mathrm{~nm}$ with baseline correction between $370-390 \mathrm{~nm}$. The UV path length was $1 \mathrm{~mm}$ and arch probes were utilized to avoid particle and air bubble interference.

\section{$215 \quad 3.4$ TIM studies}

The bioaccessibility of the test formulations $\mathrm{T} 1$ and $\mathrm{T} 2$ were studied in a gastrointestinal simulating system, TIM-1. The formulations were tested under simulated human fasted and fed gastrointestinal states at a dose of $200 \mathrm{mg}$ per run. Selection of the dose was based on the human PK study in which the food effect had been studied at that dose level. The TIM systems, previously described by Minekus et al, 1995; Blanquet, et al., 2004; Brouwers et al., 2011; Barker et al., 2014 and Verwei et al., 2016, are multi-compartmental dynamic systems, which simulate in high degree the sequentially dynamic processes in the stomach, the small intestine, and the large intestine (colon). As a result, in the TIM-1 system the administered formulation is exposed to the physiologically relevant conditions of the stomach and subsequent transit through the three sections of the small intestine. Key variables used for simulation of the fasted and fed state conditions in humans are listed in Table 5. Prior to the performance of each experiment the secretion fluids (e.g. gastric juice with enzymes, electrolytes, bile, and pancreatic juice) were freshly prepared, the $\mathrm{pH}$ electrodes calibrated, and semipermeable membrane (hollow fiber) units (pore size of $2000 \mathrm{kDa}$ ) installed. A detailed description of all prepared solutions and suppliers is described by Van den Abeele et al. (2020). 


\begin{tabular}{lll}
\hline & Fed state & Fasted state \\
\hline Gastric compartment & $300 \mathrm{~g}$ & $250 \mathrm{~g}$ \\
Intake (total) & $150 \mathrm{~g}$ & \\
Meal (European continental breakfast, ECB) & $140 \mathrm{~g}$ & $240 \mathrm{~g}$ \\
Water and artificial saliva & $10 \mathrm{~g}$ & $10 \mathrm{~g}$ \\
Gastric start fluid & $70 \mathrm{~min}$ & $20 \mathrm{~min}$ \\
Gastric emptying half time (T1/2) & $180 \mathrm{~min}$ & $60 \mathrm{~min}$ \\
Housekeeper wave & 5.2 to $1.7 \mathrm{in} 180 \mathrm{~min}$ & 3.0 to $1.8 \mathrm{in} 30 \mathrm{~min}$ \\
Gastric pH & $100 \%$ & $20 \% *$ \\
\hline Small intestinal compartments & 6.2 & 6.3 \\
Concentration bile + pancreatin & 6.5 & 6.5 \\
pH duodenum & 7.4 & 7.4 \\
pH jejunum & $6 \mathrm{~h}$ & $5 \mathrm{~h}$ \\
pH ileum & & \\
Experimental duration & & \\
\hline * 100\% bile is referring to undiluted porcine bile. The $20 \%$ means $5 \mathrm{x}$ diluted porcine bile.
\end{tabular}

In the system, the sample transit mimics the in vivo situation as far as possible. The removal of 235 released and dissolved/solubilized drug molecules from the intestinal lumen by a semipermeable membrane unit allows the determination of the so-called bio-accessible fraction, i.e. the fraction of the drug potentially available for small intestinal absorption. For fasted state, filtration rates were $9 \mathrm{~mL} / \mathrm{min}$ for jejunum and $4.5 \mathrm{~mL} / \mathrm{min}$ for ileum. For fed state conditions this was $4.5 \mathrm{~mL} / \mathrm{min}$ for the jejunum and ileum. The filtration rates are not designed to reflect

240 the in vivo absorption rates but are optimized to quantify the bioaccessible fraction correctly. The duration of the experiments in the TIM-1 system under the fasting state were 5 hours and 6 hours under the fed state. The bio-accessible fractions from the jejunum and the ileum were 
collected every 30 minutes until completion of the experiment. Ileal effluent, i.e. the non-bioaccessible fraction that emptied from the small intestine into the large intestine, was collected

245 each hour during the experiment. Upon completion of the TIM-1 experiment, the residues of the gastric, duodenum, jejunum and ileum compartments were collected separately. Any remains of the formulation were collected separately. Each compartment was rinsed twice with organic solvent. Filters were emptied and rinsed subsequently, and these rinses were pooled with the residue.

250 The samples were analyzed by using a selective liquid chromatography-tandem mass spectrometry (LC/MS/MS) analytical method based on the compound specific information. For the mobile phase $-10 \mathrm{mM}$ ammonium formate $+0.2 \%$ formic acid (v/v) and acetonitrile $+0.2 \%$ formic acid $(\mathrm{v} / \mathrm{v})$ at flow rate of $0.6 \mathrm{~mL} / \mathrm{min}$ was used in the gradient ultra pressure liquid chromatography (UPLC) system (Acquisity, Waters, MA, USA) with BEH C18 column (2.1 x

$25550 \mathrm{~mm} ; 1.7 \mu \mathrm{m}$ ). Mass spectrometer API4000 (Sciex/Applied Biosystems, MA, USA) with electro spray ionization (positive) and $3500 \mathrm{~V}$ was used for multiple reaction monitoring (MRM) analyses of the samples. The samples were collected, diluted, and analyzed within 48 hours from collection and stored at $2-10^{\circ} \mathrm{C}$.

\section{$260 \quad 3.5$ PBPK simulation}

GastroPlus software (version 9.7) with standard fasted and fed intestinal physiology and a human PBPK model was used. The systemic PK model was built based on non-clinical intra venous (i.v.) and hepatocyte data. Absorption related parameters were based on experimental in vitro values. Parameters used in simulations are presented in Table 6. More detailed 265 descriptions of the systemic PK and solubility related parameter selections are given in the supplemental material. 
ACAT $=$ advanced compartmental absorption model, $\mathrm{CL}=$ clearance, Fup $=$ fraction unbound in plasma, GFR = Glomerular filtration rate, i.v. $=$ intra venous, IVIVE $=$ in vivo in vitro extrapolation, $\mathrm{Kp}=$ partition coefficient, $\mathrm{PBPK}=$ physiologically based pharmacokinetic, Peff $=$ intestinal permeability, PSD = particle size distribution, Vss = volume of distribution.

\begin{tabular}{|c|c|c|}
\hline Parameter & Value & Rationale \\
\hline Dosage form & IR: capsule & \\
\hline Reference LogD & $5.0 @ \mathrm{pH} 7.4$ & \\
\hline $\log \mathrm{P}(\mathrm{N})-\log \mathrm{P}($ Cation $)$ & 2.9 & Fit to $\operatorname{LogD}$ versus $\mathrm{pH}$ data \\
\hline Reference solubility (mg/mL) & $1.03 @ \mathrm{pH} 3.8$ & At room temperature \\
\hline Melting point & $150^{\circ} \mathrm{C}$ & $\begin{array}{l}\text { Used to correct aqueous solubility to } \\
\text { physiological temperature }\end{array}$ \\
\hline $\begin{array}{l}\text { Temperature corrected reference } \\
\text { solubility }(\mathrm{mg} / \mathrm{mL})\end{array}$ & 3.77 & Gastroplus internal conversion tool \\
\hline $\mathrm{pKa}$ & 6.9 & From solubility versus $\mathrm{pH}$ curve fit \\
\hline SolFactor (ionised/unionised) & 9430 & From solubility versus $\mathrm{pH}$ curve fit \\
\hline Bile salt solubilisation ratio & $1.32 \mathrm{E}+04$ & FeSSIF data used \\
\hline Precipitation time (s) & 900 & Default \\
\hline Human Peff $(\mathrm{cm} / \mathrm{s} * 10 \mathrm{E}-4)$ & 5.15 & Conversion from Caco- 2 data \\
\hline Diffusion coefficient $\left(\mathrm{cm}^{\wedge} 2 / \mathrm{s}\right)$ & 0.67 & Structure based \\
\hline Experimental Fup (\%) & 0.7 & Use adjusted Fup $(0.456 \%)$ \\
\hline Blood/Plasma ratio & 0.64 & \\
\hline PBPK model & Human M 70 kg/30 Y & \\
\hline Kp calculation method & Lukacova (perfusion) & $\begin{array}{l}\text { LogD was set to } 4.1 \text { for Kp calculation } \\
\text { based on non-clinical i.v. data }\end{array}$ \\
\hline Liver total CL $(\mathrm{L} / \mathrm{h})$ & 22.3 & $\begin{array}{l}\text { Estimate based on allometric scaling and } \\
\text { hepatocyte IVIVE }\end{array}$ \\
\hline Kidney CL (L/h) & 0.051 & fu,p*GFR \\
\hline Predicted Vss (L) & 230 & \\
\hline
\end{tabular}


Predicted half-life (h)

ACAT model

PSD
7

Standard fasted or fed

3 bins
According to Table 3

Simulations included the fraction absorbed (FA\%) and plasma exposure with dose escalation (50 - $500 \mathrm{mg}$ test formulation T1) in the fed state and with a food effect (200 mg T1). The effect of particle size (T1 versus T2) was studied with virtual population simulations. The sensitivity of the model predictions was tested by simulating FA\% using a range of permeability or reference solubility values around experimental values. As ODM-204 is a weak base, its absorption may be sensitive to stomach $\mathrm{pH}$ and precipitation time. GastroPlus parameter sensitivity analysis was conducted at both fed and fasted state for these parameters.

\subsection{Human clinical study}

In this open, uncontrolled, nonrandomized, multi-centre, tolerability and pharmacokinetic firstin-man phase I dose escalation study, patients with CRPC (study NCT02344017) were randomized to receive ODM-204 in sequential cohorts of five dose levels (i.e. 50, 100, 200, 300, and 500 mg twice daily, test formulation T1) concomitantly with prednisone. (Peltola, et al., 2020). A single $50 \mathrm{mg}$ capsule was dosed in the $50 \mathrm{mg}$ cohort while multiple $100 \mathrm{mg}$ capsules were dosed for the other studies. On day 1, a predose sample and samples up to $24 \mathrm{~h}$ after dosing were taken.

The (LC/MS/MS) method was used to determine concentrations of ODM-204 in plasma. Blood samples were taken at predefined time points into blood collection tubes containing K2EDTA (ethylenediaminetetraacetate) as anticoagulant. Plasma was harvested via centrifugation, transferred to uniquely labelled polypropylene tubes and frozen at $-80^{\circ} \mathrm{C}$. At the time of 
analysis, the study samples were collected from the freezer and allowed to thaw to room temperature. Following protein precipitation with acetonitrile using OSTROTM well plates

295 (Waters, MA, USA) the samples were analysed with an AB Sciex API 6500 triple quadrupole mass spectrometer. Quantification was achieved by weighted linear regression using stable isotope labelled internal standard and the lower limit of quantitation was $1 \mathrm{ng} / \mathrm{mL}$. The area under the curve (AUC) $0-24 \mathrm{~h}$, maximum concentration $\left(\mathrm{C}_{\max }\right)$, time to reach maximum concentration $\left(\mathrm{t}_{\max }\right)$, and elimination half-life $\left(\mathrm{t}_{1 / 2}\right)$ were calculated using Phoenix WinNonlin software (Certara, Princeton, NJ, USA).

Test formulation T1 was used in the study and in addition to the dose escalation, food effect was studied at dose level of $200 \mathrm{mg}$. In the clinical study pharmacokinetic parameters were measured on day 1 and on day 8. To evaluate the prediction power of the in vitro and in silico methods under investigation, the interest is on day $1 \mathrm{PK}$ results. 


\section{Results}

\subsection{In vitro dissolution}

The USP dissolution results confirmed that dissolution rate of ODM-204 is strongly dependent on the medium used. Rapid and complete release of the API was observed in acidic conditions for the test formulation $\mathrm{T} 1$ within 30 minutes while slow and limited dissolution occurred in buffer solution at $\mathrm{pH} 5$ aqueous (Figure 1a). No precipitation was observed in the test formulation T1 two-stage test after FaSSIF addition to the vessel, but the concentration of the medium stayed at supersaturated level (Figure 1b). In the two-stage test from pH 5 to FeSSIF, slow dissolution occurred throughout the test for test formulation $\mathrm{T} 1$ even though solubility of the compound was quite high in FeSSIF (Figure 1b).

When the two-stage fasted state, test was performed using a double dose $(2 \times 100 \mathrm{mg})$ the propensity for precipitation increased slightly (Figure 1c). Further, precipitation was more apparent when the first stage at $\mathrm{pH} 3$ led to incomplete dissolution and there were undissolved particles present in the medium. In tests of the $200 \mathrm{mg}$ dose, test formulation $\mathrm{T} 2 \mathrm{was}$ used to determine if the $\mathrm{pH}$ effect is seen even with the finer particle size.

To further study the effect of API particle size on the dissolution rate, $500 \mathrm{~mL}$ FaSSIF was selected as the medium. The results obtained from these non-sink conditions showed a difference between the test formulations $\mathrm{T} 1$ and T2 (Figure 1d). As expected, the batch representing the finer API grade resulted in faster dissolution. For both formulations, dissolution was, however, very slow in the selected condition. 


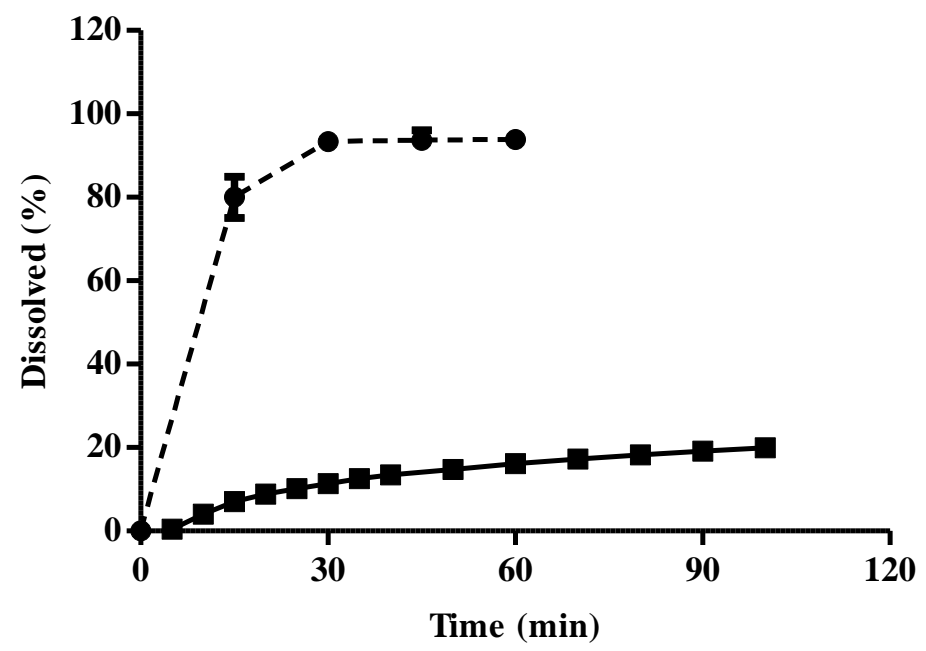

Figure 1a Dissolution of ODM-204 $100 \mathrm{mg}$ capsule (test formulation T1) $0.01 \mathrm{M} \mathrm{HCl}$ (dotted line) and in phosphate buffer $\mathrm{pH} 5$ (solid line), mean \pm standard deviation $(\mathrm{n}=6)$.

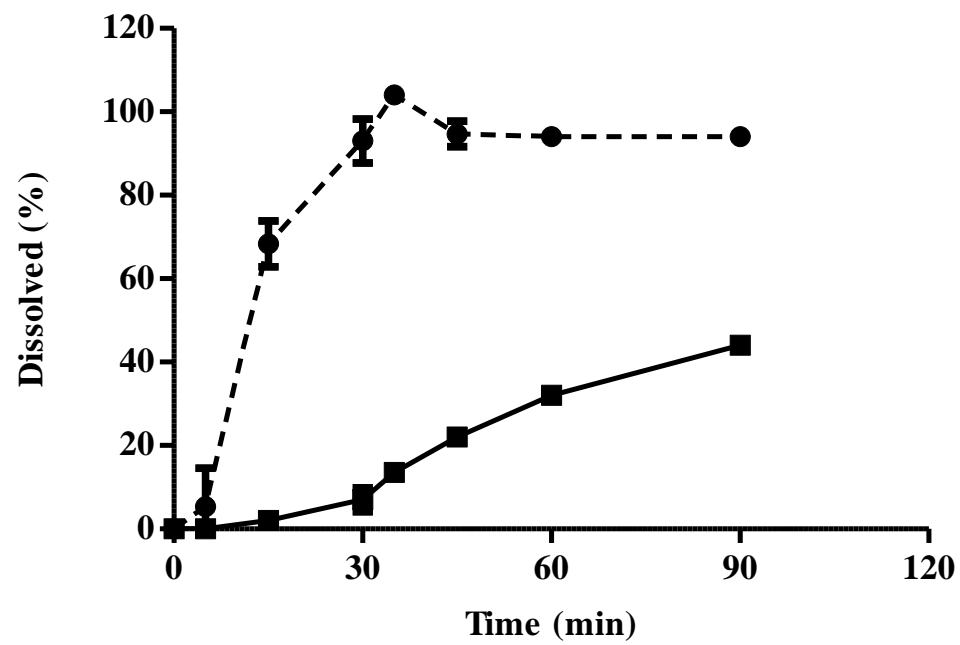

Figure 1b Dissolution of ODM-204 $100 \mathrm{mg}$ capsule (test formulation T1) in the two-stage dissolution set-up. pH 1.2 (30 min) --> FaSSIF (dotted line), pH 5 (30 min) --> FeSSIF (solid line), mean \pm standard deviation, $(\mathrm{n}=3)$. 


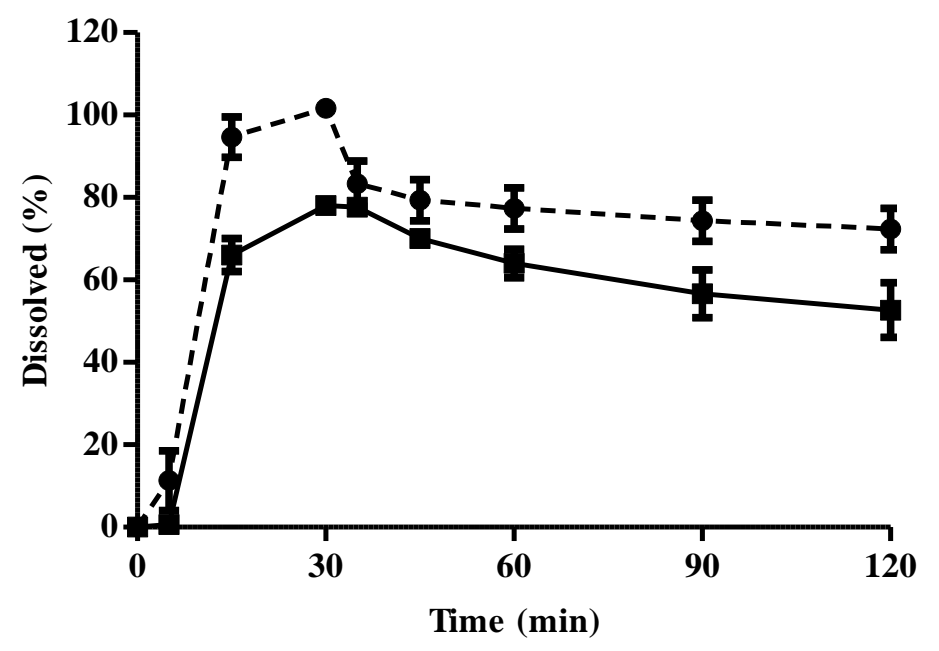

Figure 1c Dissolution of ODM-204 2x100 mg capsule (test formulation T2) in two-stage dissolution set-up. pH 1.2 (30 min) --> FaSSIF (dotted line), pH 3 (30 min) --> FaSSIF (solid line), mean \pm standard deviation $(n=3)$.

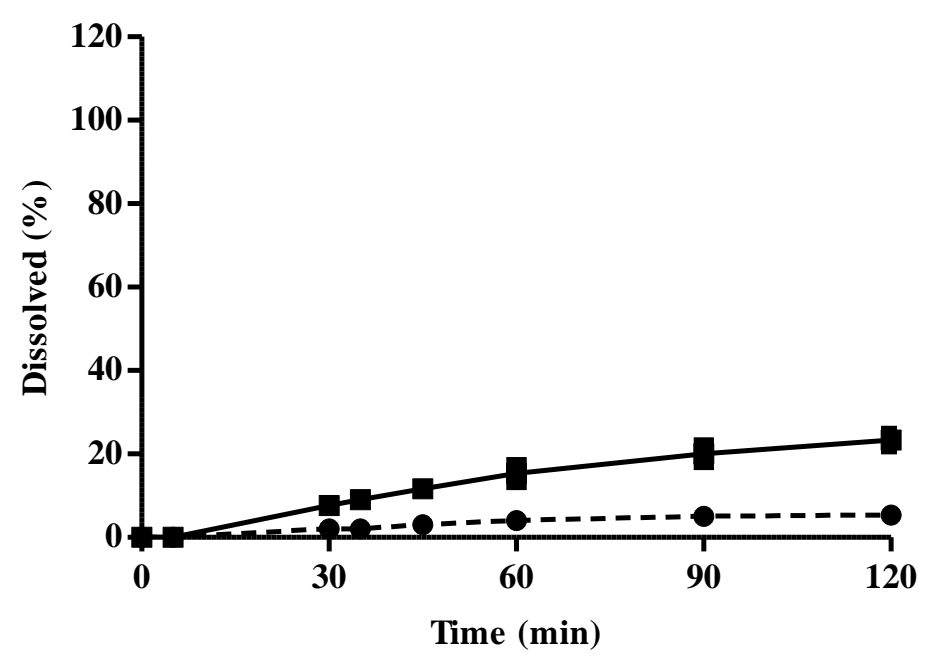

Figure 1d Dissolution of ODM-204 100 mg capsule. Test formulation T1 (dotted line) versus. test formulation T2 (solid line) API in FaSSIF, mean \pm standard deviation $(\mathrm{n}=3)$. 


\subsection{TIM-1}

An adequate total recovery of ODM-204 was observed after completion of the fasted and fed state TIM-1 experiments. The average recovery of the five runs was $87.6 \pm 2.9 \%$ and a low variation was observed in the duplicate fed state TIM-1 runs with test product $2(87.9 \pm 0.4 \%$ of intake, average \pm standard deviation, $\mathrm{n}=2$ ).

The total (jejunal + ileal) small-intestinal bioaccessibility of ODM-204 was found to be relatively low $(\leq 30 \%)$ under both fasted and fed state human GI conditions, as simulated in the TIM-1 system. The results point towards a two-fold higher bioaccessibility of ODM-204 dosed as test formulation T2 (29 - 30\% of recovery) as compared to test formulation T1 (15 - 16\% of recovery). This twofold difference in bioaccessibility of ODM-204 between T1 and T2 was observed both in the fasted and in the fed state (Table 7, Figure 2). Figure 2 shows that the maximum observed bioaccessibility values $\left(\mathrm{BA}_{\max }\right)$ were 2.6 and $3.3 \%$ of recovery for fasted and fed state conditions for $\mathrm{T} 1$ and 4.5 and $7.0 \pm 1.4 \%$ of recovery for fasted and fed states for

360 the test formulation T2. The maximum observed bioaccessibility values were measured at the 120 - 150 minutes interval in fasted state and at the 240 - 270 minutes interval in the fed state. 
Table 7

365

Jejunal, ileal and total (jejunal+ileal) bioaccessibility and ileal effluent ( $\%$ of recovery, $\mathrm{n}=1, \mathrm{n}=2$ for the fed state T2) of ODM-204 dosed as a capsule formulation (test formulations T1 or T2) with $200 \mathrm{mg}$ ODM204 under fasted and fed state conditions in TIM-1 versus predicted fraction absorbed (\%) from the PBPK model (GastroPlus).

\begin{tabular}{lcccc}
\hline & \multicolumn{2}{c}{ T1 } & \multicolumn{2}{c}{$\mathrm{T} 2$} \\
\hline & Fasted (n=1) & Fed (n=1) & Fasted (n=1) & Fed (n=2) \\
Recovery (\% of intake) & 91.9 & 84.2 & 86.1 & $87.9 \pm 0.4$ \\
Ileal effluent (\% of recovery) & 8.5 & 6.9 & 6.5 & $12.6 \pm 0.3$ \\
Residues (\% of recovery) & 75.0 & 78.1 & 63.2 & $58.1 \pm 4.1$ \\
Total (jejunal + ileal) bioaccessibility & $\mathbf{1 6 . 6}$ & $\mathbf{1 5 . 0}$ & $\mathbf{3 0 . 3}$ & $\mathbf{2 9 . 2} \pm \mathbf{3 . 9}$ \\
(\% of recovery) & & & & \\
\hline GastroPlus FA\% & $\mathbf{6 6}$ & $\mathbf{7 2}$ & $\mathbf{7 8}$ & $\mathbf{8 8}$ \\
\hline
\end{tabular}

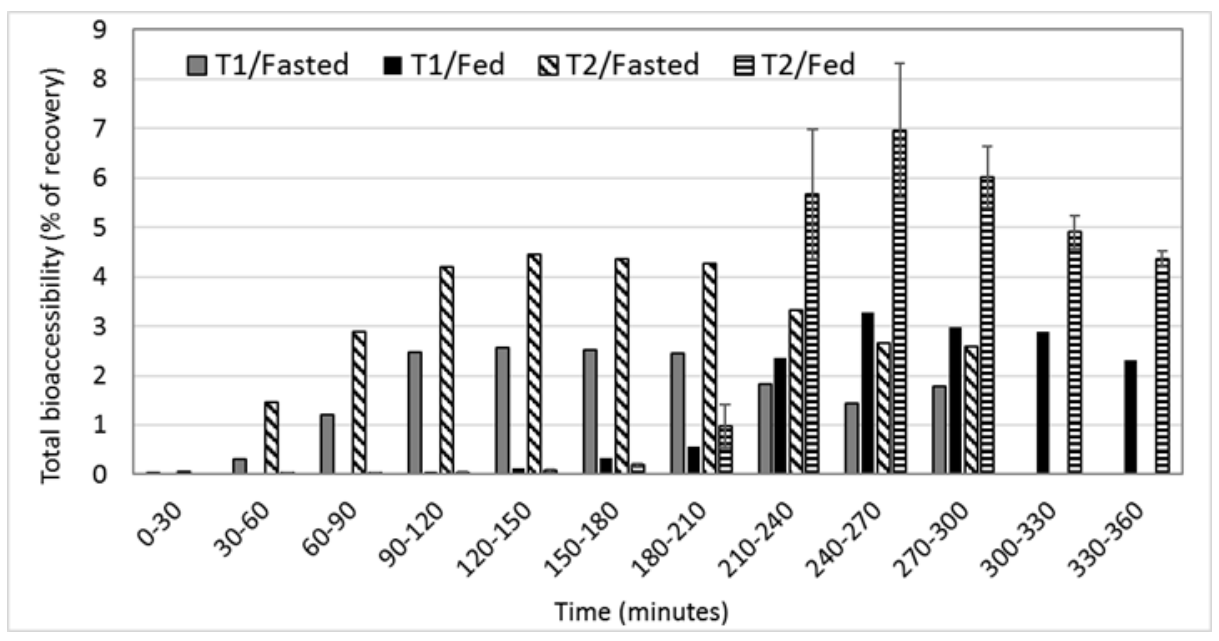

Figure 2 Results obtained from the TIM-1 system. 


\subsection{PBPK simulation}

The model parameters critical for absorption predictions (solubility, permeability, particle size distribution) were taken directly from the in vitro values. Sensitivity analyses showed that predictions are not sensitive to permeability unless the value approaches low permeability (Supplementary Figure 1). In contrast, fraction absorbed predictions are in the critical range with ODM-204 reference solubility values (Supplementary Figure 2). Therefore, the quality of in vitro solubility data was carefully reviewed, and different fittings and corrections are discussed in the supplemental material.

380 Average clinical PK parameters were predicted for the cohorts in the clinical study. Clinical results show that on day 1 the $\mathrm{AUC}_{0-12}$ of ODM-204 increased up to the $300 \mathrm{mg}$ dose (Peltola, et al., 2020) although strict dose-proportionality was not obtained. Average observed and predicted PK parameters of ODM-204 test formulation T1 are compared in Table 8. Plasma time-concentration profiles of ODM-204 test formulation T1 are shown in Figure 3. For most

385 dose levels, the average obtained AUC's were within two-fold of those predicted. The standard deviations in observed profiles suggest that there is some variation in both the rate and the extent of ODM-204 absorption. Higher doses are associated with more pronounced under prediction of AUC and $\mathrm{C}_{\max }$ (tendency for increased AUC/dose ratio). Since it is unlikely that the fraction absorbed is higher when dose increases there are probably some other saturable processes in ODM-204 disposition. Possible non-linearities in first-pass metabolism or systemic clearance are not captured in the current systemic PK model. 


\begin{tabular}{|c|c|c|c|c|c|c|}
\hline Treat & Subject & $\mathbf{C}_{\max }$ & $\mathbf{T}_{\max }$ & AUC0-24 & $\mathbf{A U C}_{\text {INF }}$ & HL \\
\hline & & $\mathrm{ng} / \mathrm{mL}$ & $\mathrm{h}$ & $\mathrm{h} * \mathrm{ng} / \mathrm{mL}$ & $\mathrm{h} * \mathrm{ng} / \mathrm{mL}$ & $\mathrm{h}$ \\
\hline \multirow[t]{3}{*}{$50 \mathrm{mg}$} & Mean $(n=3)$ & 120 & 2.2 & 700 & 860 & 9.8 \\
\hline & SD & 50 & 0.7 & 150 & 230 & 2.1 \\
\hline & $\mathrm{G}+$ prediction & 100 & 1.7 & 760 & 950 & \\
\hline \multirow[t]{3}{*}{$100 \mathrm{mg}$} & Mean $(n=3)$ & 750 & 2.7 & 2940 & 3730 & 13 \\
\hline & SD & 360 & 1.4 & 1340 & 1680 & 3.2 \\
\hline & $\mathrm{G}+$ prediction & 200 & 1.7 & 1520 & 1890 & \\
\hline \multirow[t]{3}{*}{$200 \mathrm{mg}$} & Mean $(n=3)$ & 650 & 3 & 3710 & 5190 & 12.8 \\
\hline & SD & 230 & 1 & 1950 & 3720 & 8.5 \\
\hline & $\mathrm{G}+$ prediction & 400 & 1.7 & 2990 & 3720 & \\
\hline \multirow[t]{3}{*}{200 mg FASTED } & Mean $(n=3)$ & 760 & 2.2 & 4020 & 4790 & 12.2 \\
\hline & SD & 580 & 0.3 & 2530 & 2740 & 3.8 \\
\hline & $\mathrm{G}+$ prediction & 860 & 0.4 & 3090 & 3800 & \\
\hline \multirow[t]{3}{*}{$300 \mathrm{mg}$} & Mean $(n=7)$ & 1880 & 2.9 & 11970 & 16580 & 11.5 \\
\hline & SD & 1010 & 1.1 & 8560 & 14510 & 3.5 \\
\hline & $\mathrm{G}+$ prediction & 590 & 1.7 & 4430 & & \\
\hline \multirow[t]{3}{*}{$500 \mathrm{mg}$} & Mean $(n=3)$ & 1830 & 3.4 & 10430 & 11860 & 8.1 \\
\hline & SD & 590 & 0.7 & 2840 & 2770 & 2.1 \\
\hline & $\mathrm{G}+$ prediction & 940 & 1.8 & 7170 & 8990 & \\
\hline
\end{tabular}



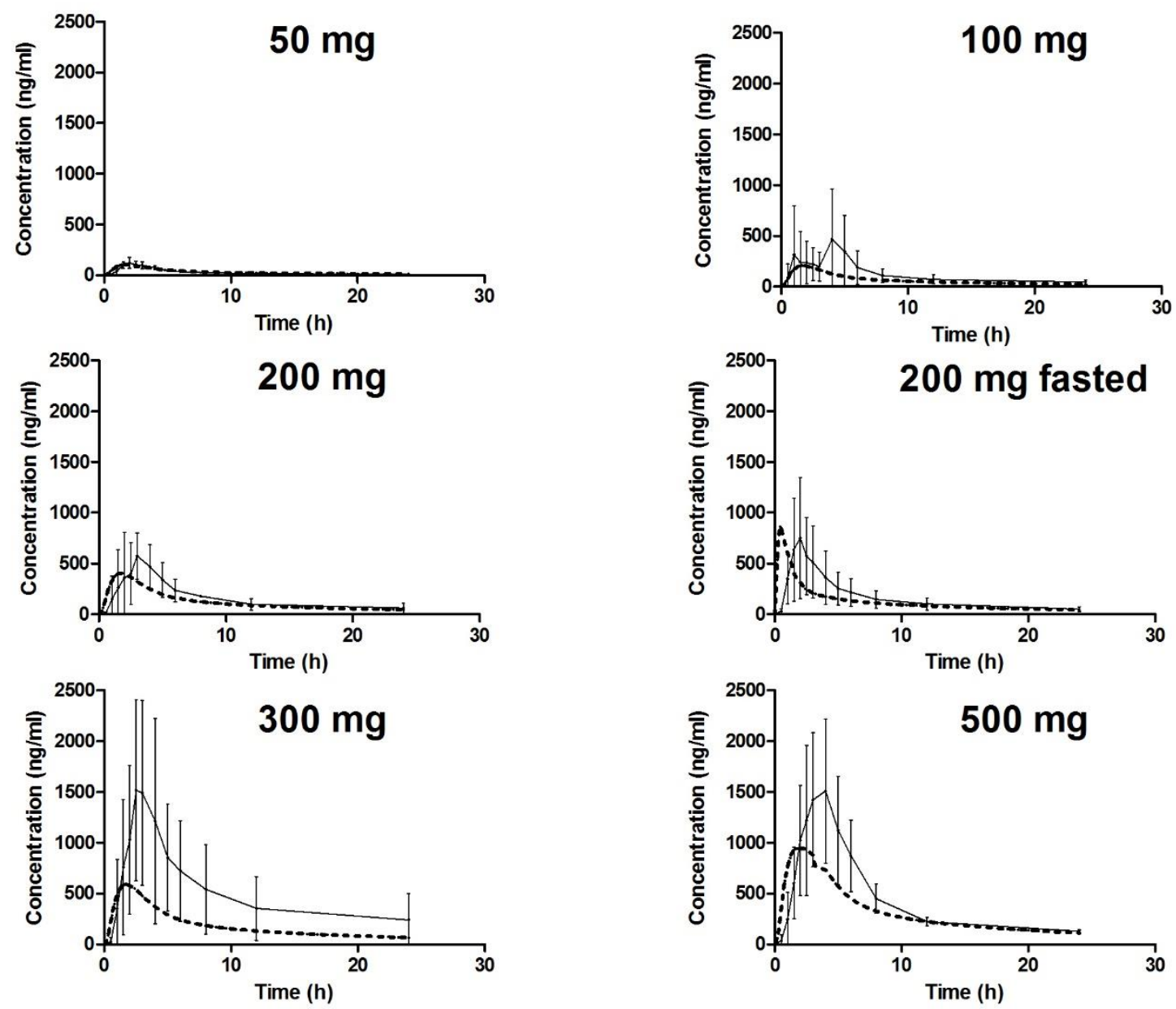

Figure 3 Concentration-time profiles of ODM-204 in human plasma after administration of ODM-204 50, 100, 200, 300 or $500 \mathrm{mg}$ bid, mean \pm SD (solid lines=observed profiles, dashed lines $=$ PBPK average predictions). Single dose (day 1) Administration: fed, $200 \mathrm{mg}$ also fasted.

The effect of particle size reduction on ODM-204 absorption was simulated using particle size distribution data of test formulation T2 with finer API (Table 3). Population simulations suggest that the average fraction absorbed is at an adequate level with both formulations (Figure 4). However, reduced particle size is expected to give a modest increase in the lower limit of absorption. In addition, the variability in exposure seen in clinical data would likely be reduced by smaller particle size. 


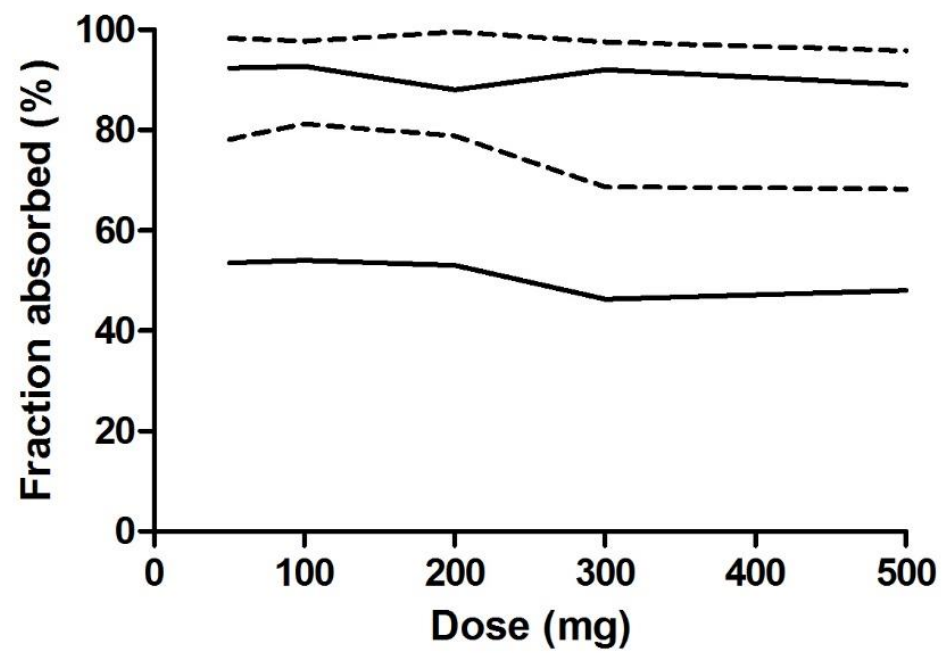

Figure 4 Predicted fraction absorbed range (min - max) at different dose levels. Population simulations (25 subjects per dose level) were conducted using test formulation T1 (solid line) or test formulation T2 (dashed line). Fed intestinal physiology was used in simulations.

Parameter sensitivity analysis on stomach $\mathrm{pH}$ and precipitation time suggest that the fasted state is more sensitive to these conditions than the fed state (Supplementary Figure 3) The fasted state can be more vulnerable since neutral stomach $\mathrm{pH}$ may be seen in the target population (e.g. proton pump inhibitor usage) while highly acidic stomach contents in the fed state is not expected to be uncommon. Precipitation may affect the absorption in the fasted state, but very rapid precipitation is not expected based on the two-stage dissolution studies (Figures $1 \mathrm{~b}$ and 1c). 


\subsection{Human clinical study}

The results show that on day 1 the $\mathrm{AUC}_{0-12}$ of ODM-204 increased in a dose-dependent manner up to the $300 \mathrm{mg}$ dose (Table 8) (Peltola, et al., 2020). At the $500 \mathrm{mg}$ dose level, a slight decrease in $\mathrm{AUC}_{0-12}$ was observed. The effect of fed state versus fasted state was compared at a dose level of $200 \mathrm{mg}$. No differences were seen in the $\mathrm{C}_{\max }$ nor the $\mathrm{AUC}_{0-12}$ values between the fasted and fed state dosing. In fasted state the $T_{\max }$ was, however, a little lower. It is of note that the subject number was low in most of the cohorts, thus the data are exploratory only.

\section{Discussion}

This study combined and compared the data obtained from in vitro dissolution, TIM-1 and in silico models, i.e. dose number, MAD and PBPK-model. The aim was to determine if these models could guide the decision making process for milling the API in the upcoming human studies. The ability of the methods was evaluated against the in vivo human PK data obtained after administration of test formulation T1, i.e. the capsule formulation manufactured from unmilled API. The dose range studied was $50-500 \mathrm{mg}$.

435 Clinical data of ODM-204 showed an increase in exposure up to $300 \mathrm{mg}$ suggesting that the fraction absorbed is not severely limited. Moreover, based on the PK study no differences were seen in the $\mathrm{C}_{\max }$ or the $\mathrm{AUC}_{0-12}$ data between fasted and fed state dosing at the $200 \mathrm{mg}$ dose level. However, the small cohort size used in the clinical study precludes definitive conclusions.

The fraction absorbed at the anticipated dose levels is the key parameter for the first-in-man predictions and to support formulation development. The simple models like dose-solubility ratio and the MAD, predicted solubility limited absorption for ODM-204 even at the lowest dose administered (Table 4). However, solubility of ODM-204 as a weak lipophilic base is 
strongly affected by both $\mathrm{pH}$ and bile salt concentrations of the dissolving medium. ODM-204 has also high permeability (Table 6). Thus, it is improbable that a single point estimate such as solubility in one medium can capture the spectrum of intestinal conditions that would be encountered in patient populations in different fasting states.

\subsection{Dissolution tests}

The solubility profile of ODM-204 indicates that a food effect may occur in vivo. Differences between fasted and fed states at least in terms of the $t_{\max }$ was suggested by the dissolution results (Figure 1b). According to the clinical PK results that difference, however, seems exaggerated.

Based on the fasted state dissolution results, high solubility in the stomach is crucial, since dissolution in the simulated intestinal fluid alone is slow (Figure 1d). Further, precipitation is not likely to affect absorption as the high concentration achieved in stomach is maintained in the intestinal condition in vitro (FaSSIF) (Figure 1b). In the fed state, release in FeSSIF was incomplete within the test time of 90 minutes (Figure 1a). Yet, high solubility and high permeability in the intestine in vivo probably compensate for the slow dissolution in the fed stomach.

In our study, the results obtained from the two-stage dissolution tests (Figure 1b) and the test in FaSSIF suggest that food and particle size effects (Figure 1d) warrant further consideration, if a closed one-compartment in vitro dissolution system can capture multifactorial gastrointestinal phenomena in vivo. That is since the system is lacking functions such as permeation and gastric motility, for example. The dissolution results, however, suggest that we should use more advanced methods to estimate the particle size and food effects more carefully. 


\subsection{TIM-1 studies}

The TIM-1 system provides more realistic intestinal conditions and for the removal of bioaccessible API by filtration over the static dissolution test. Similar cumulative values of bioaccessibility (as percentages of recovery) were obtained for ODM-204 in the fasted and fed states at a dose level of $200 \mathrm{mg}$ but the release rates differed between feeding states (Table 7, Figure 2). The difference appears logical based on the drug properties and the observations from the dissolution studies. It is also in line with the clinical results, which compared fasted and fed states. In the TIM-1 system, bioaccessible API reaches the filters in the fasting state conditions more rapidly than the fed paradigm. At the 30 - 60 minute time point API was already measurable in the filtrated samples, indicating that the formulation had disintegrated, and API had been dissolved before that time period. Soon after the bioaccessibility reaches its maximum. From 90 - 210 minutes onwards, all concentrations were comparable, indicating that a constant amount of API was dissolving over time. For the fed state conditions, almost all the bioaccessible API was collected in the filtrate from 180 minutes onwards.

Based on the TIM-1 data, the remaining question is the absolute level of absorption i.e. whether exposure could be increased several folds (fraction absorbed prediction $\sim 20 \%$ ) by for example alterations in formulation. The TIM-1 data showed that the test formulation T2 manufactured using the finer API resulted in a two-fold bioaccessibility at the dose level of $200 \mathrm{mg}$ compared to the coarser form suggesting dissolution limited bioaccessibility. These results correspond with the in vitro dissolution data and suggest accelerated dissolution and enhanced absorption of ODM-204 when API particle size is reduced 


\subsection{PBPK simulations}

The final step in absorption predictions was to combine non-clinical findings into a PBPK model for mechanistic virtual testing of ODM-204 pharmacokinetics. The main advantage of PBPK modeling is the capability to describe bioavailability more realistically. PBPK modeling allows its sensitivity to change in different parameters to be tested easily. These/our predictions followed the observed exposures reasonably well, but the model predicted increasing exposure above a $300 \mathrm{mg}$ dose. The TIM-1 prediction of fractional bioaccessibility was clearly lower than PBPK predictions, possibly owing to the lower permeability component of that system (Verwei et al., 2016). Reducing permeability in PBPK simulations resulted in a lower absorption fraction approaching the TIM-1 values (Supplementary Figure 1).

In our opinion, PBPK model development was straightforward using data of in vitro and nonclinical in vivo information for the purpose of estimating first-in-man formulation performance and exposure levels. The systemic PK model was fully linear so physiological variations or interactions after drug absorption cannot be captured with the current model. Sensitivity analyses suggested that the most crucial in vitro input parameter was solubility (Supplementary Figures 1 - 3). Despite the relative simplicity this model adequately captured the increase in exposure with dose escalation and also the minimal food effect (Table 8, Figure 3). The model suggested that on average, the fasted and fed states would result in a similar total exposure. However, the fasted state may be more susceptible to inter-individual variation since FA\% predictions showed more variation in the predicted physiological gastric $\mathrm{pH}$ range in the fasted than in fed state (Supplementary Figure 3). Therefore, simulations support selection of the fed state for early clinical trials. Simulations were also used to estimate whether formulation modifications might provide improvements in plasma exposure. The most straightforward option is to reduce the particle size in order to increase the dissolution rate. Average simulations 
suggest that FA\% would not increase considerably (Table 8). However, introducing physiological variation into the GI tract using virtual population simulations suggests that capsules containing finer API particles could reduce the inter-individual variation in exposure (Figure 4). Considering the exposure, based on the PBPK model, TIM-1 and the clinical study

515 data, it appears that the high solubility within the intestine in the fed state compensates for the limited solubility in a $\mathrm{pH}$ neutral stomach. Conversely, our results do not indicate that reprecipitation of dissolved API would affect the absorption of ODM-204.

\subsection{Summary}

The methods used gave concordant results and suggest dissolution, particularly particle size 520 limits absorption of ODM-204 within the dose range studied. All the methods provided information that can be used together to support decision making in the later phase studies, including possibly a clinical study for the test formulation T2. It is noticeable when comparing the levels of TIM-1 bioaccessibility to the PBPK model FA\% prediction and finally to the dose dependent human PK data, our data suggest that it is not possible to directly predict the fraction

525 absorbed based on the bioaccessibility data from the TIM-1 system. GI behavior of the formulation and bioaccessibility of the compound in the GI lumen is a critical step in overall oral bioavailability. But it is important to realize that the TIM predicts API bioaccessibility (fraction of the drug potentially available for small intestinal absorption) and not bioavailability. That is because processes such as mucosal transit, first pass effect, distribution and excretion are not simulated in the TIM-1 system.

Our study results support the use of predictive tools such as in vitro dissolution, TIM-1 system and the PBPK simulation together to aid decision making in the project. Although the in vitro dissolution results provided indispensable information about drug formulation, for drugs that are weak bases like ODM-204, the interpretation of the $\mathrm{pH}$ dependent solubility, dissolution 
properties and their effect on absorption is challenging (Bevernage et al., 2012; Bevernage et al., 2013). Thus, advanced methods that estimate the in vivo sink conditions and the effect of permeability, for example are needed. It is also noteworthy that the value of each measured parameter, like solubility, must be clearly understood and known because they may have a major impact on predictions and thus conclusions. Overall for effective and successful 540 development, it is advisable review the data and discuss the data in a cross-functional way between the pharmacists, analytical scientists, pharmacokineticists and modellers, bringing knowledge. In addition, when considering the development of compounds that are weak bases, more in vitro data is needed to enable utilization of the refined developability classification system, (rDCS). (Rosenberger et al., 2018). Small-scale experiments are needed to determine supersaturation/precipitation events and to support the evaluation of absorption in vivo. In the case of ODM-204, additional tests may provide greater understanding of its sensitivity release profile to factors like gastric $\mathrm{pH}$ and residence time, which could influence oral absorption (Kambayashi and Dressman, 2019). This would be important during later formulation development 


\section{Conclusions}

The data obtained from the models discussed in the paper suggests that reduction of API particle size of ODM-204 (test formulation T2) modestly improves the fraction absorbed and lowers variation in drug plasma levels in vivo. Test formulation T2 has not been tested clinically. Our

555 study, however, shows that the predictive tools used in this case, in vitro dissolution, TIM-1 system and PBPK simulation together provided valuable information when deciding whether the change in formulation would be justified during the development phase.

\section{Acknowledgements}

560 The authors wish to thank colleagues Catharina Lundberg-Niinistö, Terhi Koivu-Tikkanen, Päivi Kokkonen, Johanna Husman-Piirainen and Kirsi-Maria Rotkus for professional CMC teamwork and valuable help in data collection for this manuscript. The study was funded by Orion Pharma, Orion Corporation. 


\section{References}

Andreas, C., Rosenberger, J., Butler, J., Augustijns, P., McAllister, M., \& Abrahamsson, B. (2018). Introduction to the OrBiTo decision tree to select the most appropriate in vitro methodology for release testing of solid oral dosage forms during development. European Journal of Pharmaceutics and Biopharmaceutics, 130, 207-213.

Barker, R.;Abrahamsson, B.;\& Kruusmägi, M. (2014). Application and Validation of an Advanced Gastrointestinal In Vitro Model for the Evaluation of Drug Product Performance in Pharmaceutical Development. Journal of Pharmaceutical Sciences, $103,3704-3712$.

575 Benet, L.;Wu, C.;\& Custodio, J. (2006). Predicting drug absorption and the effects of food on oral bioavailability. Bull Techn Gattefosse, 9-16.

Bevernage, J., Brouwers, J., Annaert, P., \& Augustijns, P. (2012). Drug precipitationpermeation interplay: supersaturation in an absorptive environment. European Journal of Pharmaceutics and Biopharmaceutics, 82, 424-428.

580 Bevernage, J.;Brouwers, J.;Brewster, M. E.;\& Augustinjs, P. (2013). Evaluation of gastrointestinal drug supersaturation and precipitation: Strategies and issues. International Journal of Pharmaceutics, 453, 25-35.

Blanquet, S., Zeijdner, E., Beyssac, E., Meunier, J.-P., Denis, S., Havenaar, R., \& Alric, M. (2004). A Dynamic Artificial Gastrointestinal System for Studying the Behavior of Orally Administered Drug Dosage Forms Under Various Physiological Conditions. Pharmaceutical Research, 21, 585-591. 
Brouwers, J., Anneveld, B., Goudappel, G., \& Ducha, G. (2011). Food-dependent disintegration of immediate release fosamprenavir tablets: in vitro evaluation using magnetic resonance imaging and a dynamic gastrointestinal system. European Journal of Pharmaceutics and Biopharmaceutics, 77, 313-319.

Bueters, T.;Ploeger, B.;\& Visser, S. (2013). The virtue of translational PKPD modeling in drug discovery: selecting the right clinical candidate while sparing animal lives. Drug Discovery Today, 18, 853-862.

Butler, J., Hensb, B., Vertzoni, M., Brouwers, J., Berben, P., Dressman, J., . . Augustijns, P. (2019). In vitro models for the prediction of in vivo performance of oral dosage forms: Recent progress from partnership through the IMI OrBiTo collaboration. European Journal of Pharmaceutics and Biopharmaceutics, 136, 70-83.

Curatolo, W. (1998). Physical chemical properties of oral drug candidates in the discovery and exploratory development settings. Pharmaceutical Science \& Technology Today, 1, Pages 387-393.

Darwich, A. S.;Margolskee, A.;Pepin, X.;Aarons , L.;Galetin, A.;Rostami-Hodjegan, A.;. . . Abrahamsson, B. (2017). IMI - Oral biopharmaceutics tools project - Evaluation of bottom-up. PBPK prediction success part 3: Identifying gaps in system parameters by analysing In Silico performance across different compound classes. European Journal of Pharmaceutical Sciences, 96, 626-642.

Dressman, J., Gordon, A. L., Reppas, C., \& Shah, V. P. (1998). Dissolution testing as Prognostic Tool for Oral Drug Absorption: Immediate release dosage forms. Pharmaceutical Research, 15, 11-22. 
Galia, E., Nicolaides, E., Hörter, D., Löbenberg, R., Reppas, C., \& Dressman, J. (1998). Evaluation of various dissolution media for predicting in vivo performance of class I and II. Pharmaceutical Research, 15, 698-705.

Kambayashi, A., \& Dressman, J. (2019). Predicting the Changes in Oral Absorption of Weak Base Drugs Under Elevated Gastric pH Using an In Vitro In Silico In Vivo Approach: Case Examplesd Dipyridamole, Prasugrel and Nelfinavir. Journal of Pharmaceutical Sciences, 108, 584-591.

Kesisoglou, F., Chung, J., van Asperen, J., \& Heimbach, T. (2016). Physiologically Based Absorption Modeling to Impact Biopharmaceutics and Formulation Strategies in Drug Development-Industry Case Studies. Journal of Pharmaceutical Sciences, 105, 2723 34.

Kostewicz, E. S., Aarons, L., Bergstrand, M., Bolger, M. B., Galetin, A., Hatley, O., . . . Dressman, J. (2014). PBPK models for the prediction of in vivo performance of oral dosage forms. European Journal of Pharmaceutical Sciences, 57, 300-321.

Kostewicz, E., Abrahamsson, B., Brewster, M., Brouwers, J., Butler, J., Carlert, S., . . . Augustijns, P. (2014). In vitro models for the prediction of in vivo performance of oral dosage forms. European Journal of Pharmaceutical Sciences, 57, 342-366.

Margolskee, A., Darwich, A., Pepin, X., L. Aarons, A. G., Rostami-Hodjegan, A., Carlert, S., ... T. (2017). IMI - Oral Biopharmaceutics Tools project - Evaluation of Bottom-up PBPK Prediction Success Part 2: An Introduction to the Simulation Exercise and Overview of Results. Eur. J. Pharm. Sci., 96, 610-625.

630 Matsumura, N., Yamaura, Y., Katagi, J., Ono, S., Kim, S., Yamashita, Y., \& Sugano, K. (2018). Evaluation of Using Dogs to Predict Fraction of Oral Dose Absorbed in 
Humans for Poorly Water-Soluble Drugs. Journal of Pharmaceutical Sciences, 107, 2489-2496.

Miller, N. A.;Reddy, M. B.;Heikkinen, A. T.;Lukacova, V.;\& Parrott, N. (2019). Physiologically Based Pharmacokinetic Modelling for First-In-Human Predictions: An Updated Model Building Strategy Illustrated with Challenging Industry Case Studies. Clinical Pharmacokinetics, 58, 727-746.

Minekus, M., Marteau, P., Havenaar, R., \& Huis in 't Veld , J. (1995). Multicompartmental dynamic computer-controlled model simulating the stomach and small intestine. ATLA. Alternatives to laboratory animals. 23, 197-209.

Oh, D.-M., Curl, R. L., \& Amidon, G. L. (1993). Estimating the Fraction Dose Absorbed from Suspensions of Poorly Soluble Compounds in Humans: A Mathematical Model. Pharmaceutical Research, 10, 264-270.

Peltola, K., Bono, P., Jones, R. H., Vjaters, E., Nykänen, P., Vuorela, A., . . Massard, C. (2020). ODM-204, a Novel Dual Inhibitor of CYP17A1 and Androgen Receptor: Early Results from Phase I Dose Escalation in Men with Castration-resistant Prostate Cancer. European Urology Focus, 6, 63-70.

Rosenberger, J.;Butler, J.;\& Dressman, J. (2018). Application of a refined Developability classification system. Journal of Pharmaceutical Sciences, 107, 2020-2032.

650 Van den Abeele, J.;Kostantini, C.;Barker, R.;Kourentas, A.;Mann, J. C.;Vertzoni, M.;. . Augustijns, P. (2020). The effect of reduced gastric acid secretion on the gastrointestinal disposition of a ritonavir amorphous solid dispersion in fasted healthy volunteers: an in vivo - in vitro investigation. European Journal of Pharmaceutical Sciences, 151, 105377. 
655 Verwei, M.;Minekus, M.;Zeijdner, E.;\& Schilderink, R. (2016). Evaluation of two dynamic in vitro models simulating fasted and fed state conditions in the upper gastrointestinal tract (TIM-1 and tiny-TIM) for investigating the bioaccessibility of pharmaceutical compounds from oral dosage forms. International Journal of Pharmaceutics, 498, 178-186.

660 

absorbed of $200 \mathrm{mg}$ ODM-204 in fed state. Result using parameter values in 
Table 6 is shown as open square.

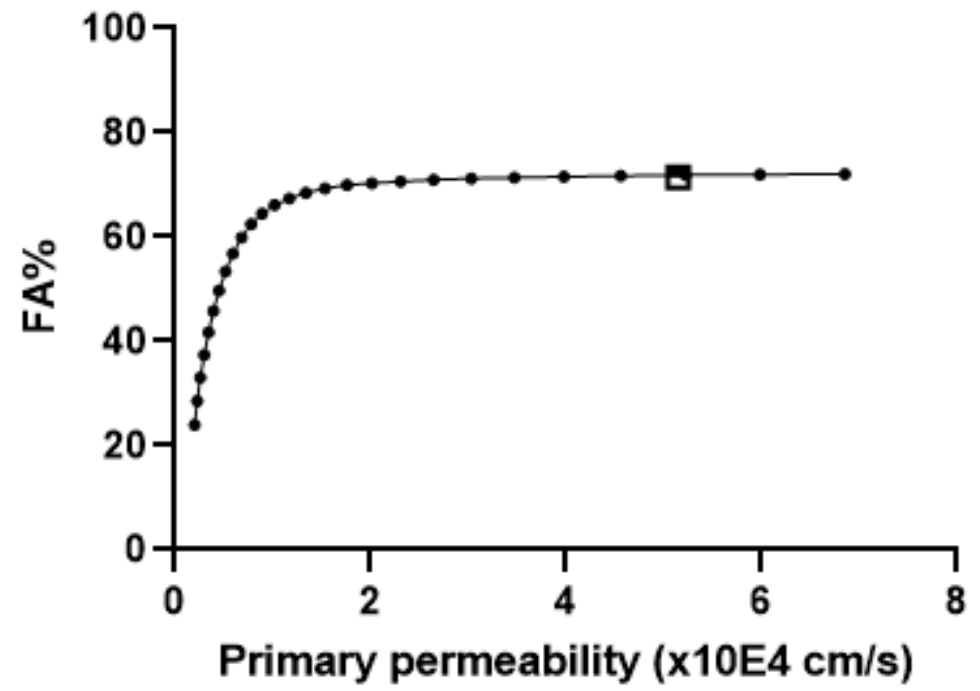



absorbed of $200 \mathrm{mg}$ ODM-204 in fed state. Result using parameter values in 
Table 6 is shown as open square.

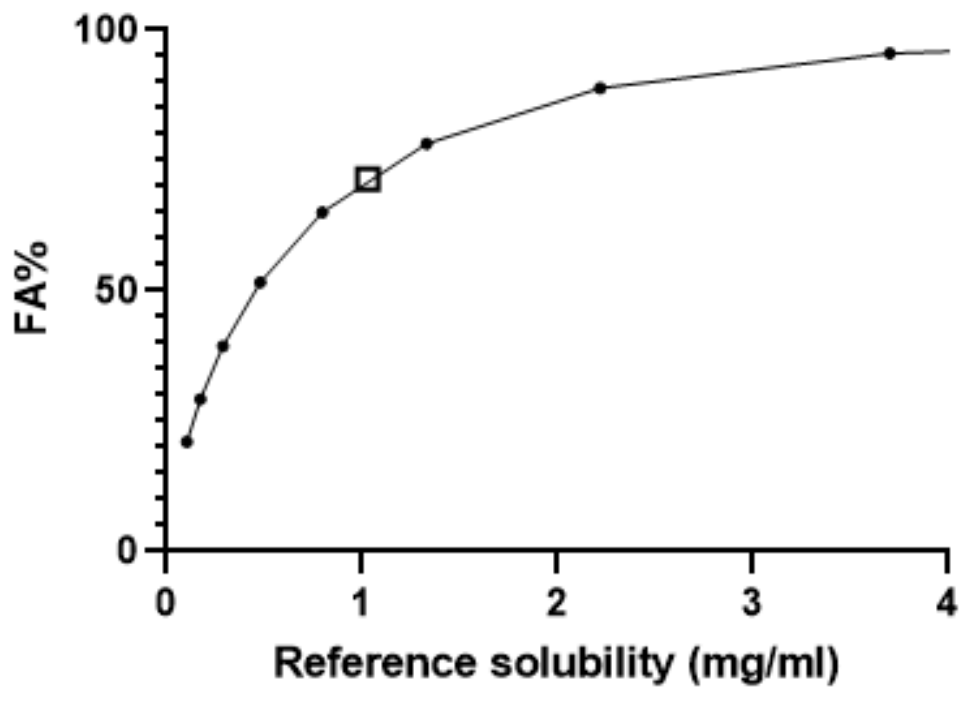


Supplementary Figure 3

Sensitivity analysis on the effect of stomach $\mathrm{pH}(1-7)$ and precipitation time (9-

9000 s) on predicted fraction absorbed of $200 \mathrm{mg}$ ODM-204 in both fasted (gray surface) and fed (transparent surface) state. Results using parameter values in 
Table 6 for fasted (black circle) and fed (black square) state are included.

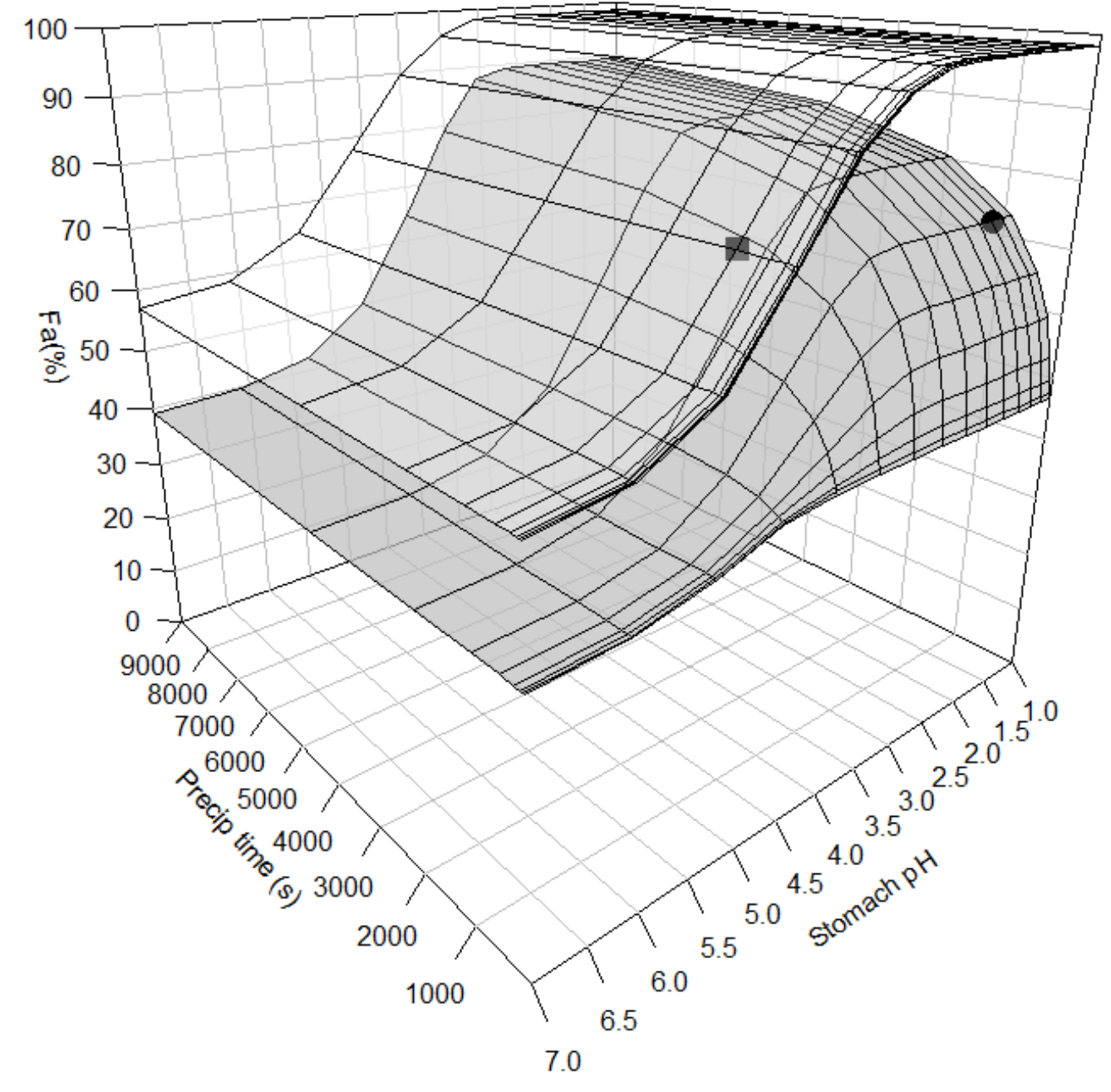

